\title{
Persistent Wheeze in Infants: A Guide for General Pediatricians
}

\author{
Yolanda Yu, DO; Charles R. Esther, Jr., MD, PhD; Clement L. Ren, MD, MBA; and Ceila Loughlin, MD
}

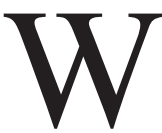

ABSTRACT

Infants with persistent wheeze is a common diagnostic challenge for the general pediatrician because of the broad differential diagnoses. The initial diagnostic approach should include a comprehensive history, physical examination, and chest radiography. Additional testing may be warranted. Involvement of a pediatric pulmonary subspecialist may also be indicated. [Pediatr Ann. 2019;48(3):e110-e114.]

heeze is one of the most common respiratory symptoms in the pediatric population. The Tucson Children's Respiratory Study (TCRS), a longitudinal birth cohort study of healthy full-term infants, demonstrated that $34 \%$ of children had at least one episode of wheeze before age 3 years and $50 \%$ of children wheezed in the first 6 years of life. ${ }^{1}$ Similarly, a large prospective, population-based longitudinal birth cohort study in Sweden found that

$25 \%$ of children wheezed before age 2 years. $^{2}$

Several risk factors have been implicated in recurrent or persistent wheeze, typically defined as three or more episodes of wheeze in 1 year (Table 1). ${ }^{1,3}$ Although multiple risk factors are associated with persistent and recurrent wheeze, the "Estudio Internacional de Sibilancias en Lactantes [International Study of Wheezing in Infants]" (EISL), a populationbased study in Latin America and
Yolanda Yu, DO, is a Fellow, Division of Pediatric Pulmonology, Department of Pediatrics, University of North Carolina at Chapel Hill. Charles R. Esther, Jr., MD, PhD, is a Professor of Pediatrics, the Pediatric Pulmonology Training Program Director, and the Director of Clinical Operations, Division of Pediatric Pulmonology, Department of Pediatrics, University of North Carolina at Chapel Hill. Clement L. Ren, MD, MBA, is a Professor of Clinical Pediatrics, Department of Pediatrics, Indiana University School of Medicine; and the Cystic Fibrosis Center Director, and the Associate Division Chief, Pediatric Pulmonology, Section of Pulmonology, Allergy \& Sleep Medicine, Riley Children's Health. Ceila Loughlin, MD, is an Associate Professor of Pediatrics, Division of Pediatric Pulmonology, Department of Pediatrics, University of North Carolina at Chapel Hill.

Address correspondence to Charles R. Esther, Jr., MD, PhD, Division of Pediatric Pulmonology, Department of Pediatrics, University of North Carolina at Chapel Hill, 450 MacNider, Campus Box \#7217, 333 S. Columbia Street, Chapel Hill, NC 27599; email: Charles_esther@med.unc.edu.

Disclosure: The authors have no relevant financial relationships to disclose.

doi:10.3928/19382359-20190222-02
Europe, showed that nursery school attendance and colds during the first 3 months of life were the most important risk factors. ${ }^{3}$ The EISL also found that breast-feeding for more than 3 months was a protective factor against wheezing. ${ }^{3}$

\section{DIAGNOSIS AND MANAGEMENT}

The initial history should include a detailed account of the wheezing episodes, including onset, frequency, duration, and associated palliative and provoking factors. Birth history (eg, prematurity, respiratory distress at birth), medical history (eg, eczema, allergic rhinitis), family history (eg, atopy, asthma), and environmental history (eg, cigarette smoke exposure, day care attendance) are also important to review. Physical examination should include evaluation of respiratory rate and oxygen saturation, in addition to a thorough respiratory assessment. ${ }^{4}$

With regards to diagnostic testing, an initial chest radiograph with posteroanterior and lateral views is recommended. ${ }^{4}$ Further diagnostic testing may not be needed for infants whose wheeze responds well to commonly used therapies such as bronchodilators and inhaled corticosteroids. However, as outlined below, more advanced testing may be needed for infants who do not respond to conventional therapy. ${ }^{5}$ 


\section{DIFFERENTIAL DIAGNOSES}

The most common causes of persistent and recurrent wheeze include infections, asthma, allergies, and gastroesophageal reflux disease. However, the differential for infantile wheeze is broad and includes protracted bacterial bronchitis, anatomic abnormalities, swallowing dysfunction, and others. ${ }^{5}$ A referral to a pediatric pulmonary subspecialist may be helpful to help establish the diagnosis and facilitate any needed testing.

\section{INFECTIONS}

Viral infections are one of the most common causes of wheeze in infancy. The TCRS demonstrated that in the first year of life, the prevalence of wheezing with lower respiratory illnesses was $32 \%{ }^{6}$ The TRCS also showed that this was $17.3 \%$ in the second year of life and $12 \%$ in the third year of life. ${ }^{6}$

Risk factors for wheezing with lower respiratory illnesses include maternal smoking and maternal age. Maternal smoking is associated with earlier age of first lower respiratory illness and increased incidence of wheezing with lower respiratory illness. ${ }^{6,7}$ Younger maternal age is associated with an increased incidence of wheeze with lower respiratory tract illnesses. ${ }^{6,8}$ Breast-feeding is a protective factor in the first 4 months of life for wheezing associated with respiratory illnesses. ${ }^{6,9}$

Bronchiolitis was the most commonly diagnosed initial lower respiratory tract infection in the TCRS. ${ }^{10}$ Bronchiolitis typically presents with rhinorrhea, cough, wheeze, tachypnea, retractions and increased work of breathing. ${ }^{11}$ It is often diagnosed based on history and clinical presentation. Virologic testing is not routinely recommended. ${ }^{11}$ Chest radiography in acute bronchiolitis is reserved for infants admitted to the intensive care unit or with pulmonary complications. ${ }^{11}$

Respiratory syncytial virus (RSV) is the most common viral cause of bronchiolitis. ${ }^{11}$ Other viral etiologies of bronchiolitis include human rhinovirus, human metapneumovirus, influenza, adenovirus, coronavirus, and parainfluenza virus. ${ }^{11}$ RSV infection before age 3 years is associated with an increase in subsequent wheezing in the first 10 years of life, but not an increase in asthma prevalence at age 13 years. ${ }^{12}$

The mainstay of treatment for bronchiolitis is supportive care. Albuterol, epinephrine, systemic corticosteroids, and chest physiotherapy are no longer recommended in the absence of other conditions. ${ }^{11}$ Nebulized hypertonic saline is advised only for treatment in hospitalized infants. ${ }^{11}$

\section{ASTHMA}

Asthma is one of the most common etiologies of persistent wheezing in children. It is also the most common chronic medical disease in the pediatric population and a leading cause of hospitalization. ${ }^{13}$ Uncontrolled asthma results in significant morbidity, mortality, and health care costs in children. ${ }^{13}$

The diagnosis of asthma in infants can be challenging, particularly when trying to distinguish it from viral-mediated wheeze. Because there is no test available that can easily diagnose asthma, the diagnosis is often made based on symptom history, family history, and physical examination findings. Symptoms characteristic of asthma include wheeze, nonproductive cough, shortness of breath, and activity limitation. Adjunctive clinical tests can also be helpful in diagnosis. The Global Initiative for Asthma guidelines note the following to be useful diagnostic aids: therapeutic trial of inhaled corticoste-
TABLE 1.

\section{Risk Factors for Persistent Wheeze}

Nursery school attendance

Rhinitis apart from colds

Colds during the first 3 months of life

Eczema during the first year of life

Maternal smoking

Mold stains on the walls of the household

Maternal asthma

Hispanic ethnic background

Male gender

Adapted from Martinez et al. ${ }^{1}$ and Garcia-Marcos et al. ${ }^{3}$

roids and as needed short-acting beta2agonists, atopy testing, chest radiography, lung function testing (in older children), measuring exhaled nitric oxide, and asthma predictive indices. ${ }^{14}$

The Asthma Predictive Index (API) (Table 2) was developed to aid in the early identification of children at high risk for developing asthma. It has been shown that $68 \%$ of school-aged children with a negative API did not develop asthma, whereas $76 \%$ of children with a positive API had symptoms of asthma at least once between ages 6 and 13 years. ${ }^{6,15}$

Since the API was developed, other predictive models have been created. The modified Asthma Predictive Index (mAPI) (Table 3) is one such clinical tool. The mAPI is for use in children younger than age 3 years and with more than four wheezing episodes per year. ${ }^{16}$ A study demonstrated that a positive mAPI increased the probability of future asthma diagnosis. ${ }^{16}$ It should be noted that all of these indices were created to predict future asthma and not the clinical response to asthma therapies in infants.

If the clinician suspects asthma and respiratory symptoms are frequent or 
uncontrolled, current guidelines recommend initiating controller therapy. ${ }^{14,17}$ Asthma treatment in children should follow a stepwise approach. Inhaled short-acting beta2-agonists are used for symptomatic relief. When starting asthma controller therapy, an inhaled corticosteroid is the preferred initial treatment. Response to therapy should be closely monitored. After 3 months of well-controlled symptoms, a stepdown in treatment may be considered. Consider a step-up in therapy, if symptoms are persistent 4 to 6 weeks after beginning treatment, but only after differential diagnosis, medication adherence, and correct inhaler technique are reviewed. ${ }^{17}$ If further increases in asthma therapy are considered, a referral to a pediatric asthma specialist is recommended.

\section{ALLERGIES}

Allergies are one consideration in persistent wheeze in infancy. The Generation R Study found no significant association between early introduction of cow's milk, peanuts, soy, gluten, and hen's egg with wheezing at any age. ${ }^{18}$ The American Thoracic Society (ATS) clinical practice guidelines do not recommend empiric food avoidance in "infants without eczema who have persistent wheezing despite treatment with standard therapies." 5

\section{GASTROESOPHAGEAL REFLUX DISEASE}

Gastroesophageal reflux disease (GERD) is a common cause of persistent wheezing. In a study of children younger than age 2 years with recurrent and persistent wheezing, GERD contributed to wheeze in $37 \%$ of patients. ${ }^{19}$

Although wheeze is one common symptom of GERD, other associated symptoms include cough, feeding refusal, discomfort, dysphagia, failure
TABLE 2.

\section{Asthma Predictive Index}

\begin{tabular}{|c|c|}
\hline $\begin{array}{l}\text { Major Criteria } \\
\text { (at least } 1 \text { major) }\end{array}$ & $\begin{array}{l}\text { Minor Criteria } \\
\text { (at least } 2 \text { minor) }\end{array}$ \\
\hline $\begin{array}{l}\text { Physician- } \\
\text { diagnosed } \\
\text { parental asthma } \\
\text { Physician- } \\
\text { diagnosed atopic } \\
\text { dermatitis }\end{array}$ & $\begin{array}{l}\text { Wheezing apart } \\
\text { from colds } \\
\text { Physician- } \\
\text { diagnosed allergic } \\
\text { rhinitis } \\
\text { Peripheral blood } \\
\text { eosinophilia }\end{array}$ \\
\hline
\end{tabular}

Adapted from Taussig et al. ${ }^{\circ}$

to thrive, Sandifer syndrome, recurrent regurgitation, stridor, and hoarseness. ${ }^{20}$

Recent clinical guidelines from ATS recommend 24-hour esophageal $\mathrm{pH}$ monitoring for "infants with persistent wheeze that is not relieved by bronchodilators, inhaled corticosteroids, or systemic corticosteroids." 5 Studies such as barium contrast studies, ultrasonography, esophago-gastro-dudodenoscopy, and scintigraphy are not recommended for the diagnosis of GERD in infants. ${ }^{5,20}$ Previously empiric trials of anti-reflux therapy were given but this is no longer advised in infants. ${ }^{20}$ Instead, the Pediatric Gastroesophageal Reflux Clinical Practice Guidelines suggest thickening feeds and adjusting feeding frequency and volume to avoid overfeeding. ${ }^{20}$ If these interventions are unsuccessful, consider a 2- to 4-week trial of amino-acid-based or extensively hydrolyzed protein-based formula. If nonpharmacologic treatments fail to improve GERD, referral to a pediatric gastroenterologist is recommended. ${ }^{20}$

\section{PROTRACTED BACTERIAL BRONCHITIS}

Another cause of wheezing in infancy is protracted bacterial bronchitis (PBB). This diagnosis is characterized
TABLE 3.

\section{Modified Asthma Predictive Index}

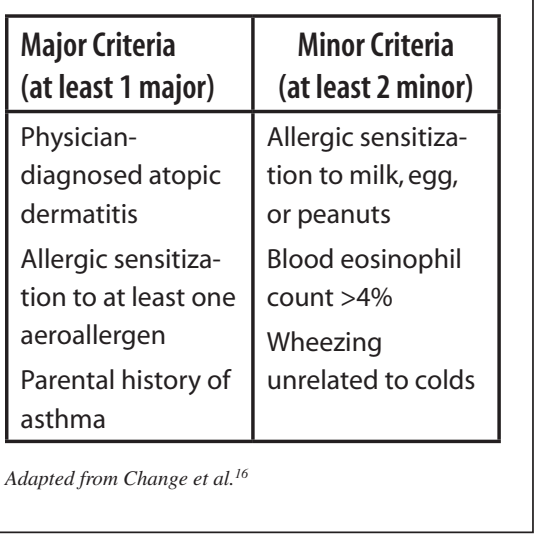

by the presence of a chronic wet or productive cough for greater than 4 weeks that resolves with a 2- to 4-week course of an appropriate oral antibiotic. ${ }^{21} \mathrm{Al}-$ though chronic cough is the defining symptom in $\mathrm{PBB}$, wheezing has also been reported. ${ }^{21}$ ATS guidelines also recommend bronchoscopy with bronchoalveolar lavage (BAL) in infants with persistent wheeze despite standard therapies. ${ }^{5}$ Common bronchoscopic findings in children with PBB include airway malacia, bronchitis, and purulent secretions. ${ }^{21,22}$ The most common bacterial pathogens detected in BAL cultures from children diagnosed with PBB include Haemophilus influenzae, Streptococcus pneumoni$a e$, and Moraxella catarrhalis..$^{21}$ Management of PBB is typically a 2- to 4 -week course of an appropriate oral antibiotic, although the 2008 British Thoracic Society guidelines suggested a 4- to 6-week course of antibiotics and chest physiotherapy for children with PBB. ${ }^{22,23}$

\section{SWALLOWING DYSFUNCTION}

Swallowing dysfunction is another cause of persistent wheezing in infancy. 
Sheikh et al. ${ }^{24}$ described 13 neurologically normal infants with chronic respiratory symptoms secondary to aspiration. Their respiratory symptoms resolved once their aspiration resolved. ${ }^{24}$ Studies have reported that $10 \%$ to $15 \%$ of infants with respiratory symptoms but not a chronic illness have swallowing dysfunction. ${ }^{5}$

Other signs and symptoms of aspiration include coughing, choking and/or gagging during feeding, apnea, bradycardia, recurrent pneumonia or bronchitis, and failure to thrive. ${ }^{24}$ Recent ATS guidelines recommend swallow function study in "infants without neurologic pathology with persistent wheeze that is not relieved by bronchodilators, inhaled corticosteroids or systemic corticosteroids." ${ }^{5}$ Treatment often includes changes to the feeding regimen. ${ }^{24}$

\section{FOREIGN BODY ASPIRATION}

Although rare, foreign body aspiration can be one explanation for persistent wheeze. One study showed that wheezing was a common symptom and physical examination finding in children hospitalized with suspected foreign body aspiration..$^{25}$ Chest radiography should be obtained in children with suspected foreign body aspiration. ${ }^{26}$ Management is rigid bronchoscopic removal of the aspirated foreign body. ${ }^{26}$

\section{ANATOMIC ABNORMALITIES}

Anatomic abnormalities can cause persistent wheezing, although this is more prevalent in infants who have failed standard therapies. In a study of 603 children with chronic respiratory symptoms who underwent bronchoscopic evaluation, $34(5.6 \%)$ had tracheomalacia and/or bronchomalacia. ${ }^{27}$ Other anatomic abnormalities that may present with wheeze include vascular rings, vascular slings, and airway compression by vascular structures. ${ }^{5}$ ATS recommends flexible bronchoscopy in infants with persistent wheeze who have failed conventional therapies. ${ }^{5}$ If airway evaluation reveals tracheomalacia and/or bronchomalacia, management is often observation, although occasionally intervention is indicated. ${ }^{5}$ If a vascular ring, a vascular sling, or airway compression due to vascular structures is seen, surgical correction is often performed on symptomatic patients. ${ }^{5}$

\section{CYSTIC FIBROSIS}

Cystic fibrosis (CF) is a rare cause of wheezing in infants. It is a life-limiting autosomal recessive disorder resulting from mutation of the $\mathrm{CF}$ transmembrane conductance regulator (CFTR) gene. ${ }^{28}$ Clinical presentation varies depending on the CF genotype, but can include failure to thrive, recurrent respiratory infections, and decreased lung function. ${ }^{29}$ The majority of new CF diagnoses are the result of positive newborn screen (NBS) ${ }^{28}$ Although NBS allows for early diagnosis, confirmation of the diagnosis with a sweat chloride test is still recommended. ${ }^{28}$ A positive sweat chloride test will demonstrate elevated sweat chloride concentration indicative of a CFTR defect. ${ }^{28}$ Children with CF should be treated at an accredited $\mathrm{CF}$ center. ${ }^{29}$

\section{PRIMARY CILIARY DYSKINESIA}

Primary ciliary dyskinesia (PCD) is another rare cause of wheezing in infants. PCD is an autosomal recessive disorder characterized by motile ciliary dysfunction. Characteristic findings include daily wet productive cough, daily rhinosinusitis, history of neonatal respiratory distress syndrome, and organ laterality defects. ${ }^{30}$ Chronic otitis media with effusion is also often seen in PCD. ${ }^{30}$ Diagnostic testing includes nasal nitric oxide measurement, genetic testing, and electron microscopy of ciliary ultrastructure ${ }^{30}$ Children with PCD should be managed at a PCD foundation clinical center or by a multidisciplinary team at an accredited CF center. ${ }^{31}$

\section{CONCLUSION}

In summary, persistent wheezing in infants is a commonly encountered complaint with multiple etiologies. Although respiratory viral infections and asthma represent the most common etiologies, other diagnoses should be considered for infants who do not respond to standard therapies. A detailed history, thorough physical examination, and chest radiography will help narrow the differential diagnoses. Further evaluation should be tailored to the likely etiology. Consultation with a pediatric pulmonary subspecialist may also be warranted depending on severity of respiratory symptoms and suspected etiology.

\section{REFERENCES}

1. Martinez FD, Wright AL, Taussig LM, Holberg CJ, Halonen M, Morgan WJ. Asthma and wheezing in the first six years of life. The Group Health Medical Associates. N Engl J Med. 1995;332(3):133-138.

2. Neuman A, Bergstrom A, Gustafsson P, et al. Infant wheeze, comorbidities and school age asthma. Pediatr Allergy Immunol. 2014;25(4):380-386. doi:10.1111/pai.12223.

3. Garcia-Marcos L, Mallol J, Sole D, Brand PL; EISL Study Group. International study of wheezing in infants: risk factors in affluent and non-affluent countries during the first year of life. Pediatr Allergy Immunol. 2010;21(5):878-888. doi:10.1111/j.13993038.2010.01035.x.

4. Kliegman R, Behrman R, Jenson H, Stanton B, eds. Nelson Textbook of Pediatrics. Philadelphia, PA: Saunders/Elsevier; 2007.

5. Ren CL, Esther CR, Jr., Debley JS, et al. Official American Thoracic Society Clinical Practice Guidelines: diagnostic evaluation of infants with recurrent or persistent wheezing. Am J Respir Crit Care Med. 2016;194(3):356373. doi:10.1164/rccm.201604-0694ST.

6. Taussig LM, Wright AL, Holberg CJ, Halonen M, Morgan WJ, Martinez FD. Tucson Children's Respiratory Study: 1980 to present. J Allergy Clin Immunol. 2003;111(4):661-675; quiz 676.

7. Wright AL, Holberg C, Martinez FD, Taussig LM. Relationship of parental smoking to 
wheezing and nonwheezing lower respiratory tract illnesses in infancy. Group Health Medical Associates. J Pediatr. 1991;118(2):207214.

8. Martinez FD, Wright AL, Holberg CJ, Morgan WJ, Taussig LM. Maternal age as a risk factor for wheezing lower respiratory illnesses in the first year of life. Am J Epidemiol. 1992;136(10):1258-1268.

9. Wright AL, Holberg CJ, Martinez FD, Morgan WJ, Taussig LM. Breast feeding and lower respiratory tract illness in the first year of life. Group Health Medical Associates. BMJ. 1989;299(6705):946-949.

10. Wright AL, Taussig LM, Ray CG, Harrison HR, Holberg CJ. The Tucson Children's Respiratory Study. II. Lower respiratory tract illness in the first year of life. Am J Epidemiol. 1989;129(6): 1232-1246.

11. Ralston SL, Lieberthal AS, Meissner HC, et al. Clinical practice guideline: the diagnosis, management, and prevention of bronchiolitis. Pediatrics. 2014;134(5):e1474-e1502. doi:10.1542/peds.2015-2862.

12. Stein RT, Sherrill D, Morgan WJ, et al. Respiratory syncytial virus in early life and risk of wheeze and allergy by age 13 years. Lancet. 1999;354(9178):541-545. doi:10.1016/ S0140-6736(98)10321-5.

13. Ferrante G, La Grutta S. The burden of pediatric asthma. Front Pediatr. 2018;6:186. doi:10.3389/fped.2018.00186

14. Global Initiative for Asthma. Global strategy for asthma management and prevention, 2018. https://ginasthma.org/wp-content/ uploads/2018/04/wms-GINA-2018-reportV1.3-002.pdf. Accessed March 4, 2019.

15. Castro-Rodriguez JA, Holberg CJ, Wright AL, Martinez FD. A clinical index to define risk of asthma in young children with recurrent wheezing. Am J Respir Crit Care Med. 2000;162(4 Pt 1):1403-1406. doi:10.1164/ ajrccm.162.4.9912111.

16. Chang TS, Lemanske RF, Jr., Guilbert TW, et al. Evaluation of the modified asthma predictive index in high-risk preschool children. $J$ Allergy Clin Immunol Pract. 2013;1(2):152156. doi:10.1016/j.jaip.2012.10.008.

17. National Asthma Education and Prevention Program. Expert Panel Report 3 (EPR-3): Guidelines for the Diagnosis and Management of Asthma-Summary Report 2007. J Allergy Clin Immunol Pract. 2007;120(suppl):S94S138. doi:10.1016/j.jaci.2007.09.043.

18. Tromp, II, Kiefte-de Jong JC, Lebon A, et al. The introduction of allergenic foods and the development of reported wheezing and eczema in childhood: the Generation R study. Arch Pediatr Adolesc Med. 2011;165(10):933-938. doi:10.1001/archpediatrics.2011.93.

19. Patra S, Singh V, Chandra J, Kumar P, Tripathi M. Gastro-esophageal reflux in early childhood wheezers. Pediatr Pulmonol. 2011;46(3):272-277. doi:10.1002/ ppul.21363.

20. Rosen R, Vandenplas Y, Singendonk M, et al. Pediatric Gastroesophageal Reflux Clinical Practice Guidelines: Joint Recommendations of the North American Society for Pediatric Gastroenterology, Hepatology, and Nutrition and the European Society for Pediatric Gastroenterology, Hepatology, and Nutrition. $J$ Pediatr Gastroenterol Nutr. 2018;66(3):516554. doi:10.1097/MPG.0000000000001889.

21. Kantar A, Chang AB, Shields MD, et al. ERS statement on protracted bacterial bronchitis in children. Eur Respir J. 2017;50(2).

22. Chang AB, Upham JW, Masters IB, et al. Protracted bacterial bronchitis: The last decade and the road ahead. Pediatr Pulmonol. 2016;51(3):225-242. pii:1602139. doi:10.1183/13993003.02139-2016.

23. Shields MD, Bush A, Everard ML, McKenzie S, Primhak R. BTS guidelines: recommendations for the assessment and management of cough in children. Thorax. 2008;63(suppl 3):iii1-iii15. doi:10.1136/thx.2007.077370.

24. Sheikh S, Allen E, Shell R, et al. Chronic aspiration without gastroesophageal reflux as a cause of chronic respiratory symptoms in neurologically normal infants. Chest. 2001;120(4):1190-1195.

25. Paksu S, Paksu MS, Kilic M, et al. Foreign body aspiration in childhood: evaluation of diagnostic parameters. Pediatr Emerg Care. 2012;28(3):259-264. doi:10.1097/ PEC.0b013e3182494eb6.

26. Taskinlar H, Bahadir GB, Erdogan C, Yigit D, Avlan D, Nayci A. A diagnostic dilemma for the pediatrician: radiolucent tracheobronchial foreign body. Pediatr Neonatol. 2017;58(3):264-269. doi:10.1016/j.pedneo.2016.07.003.

27. Yalçin E1, Dogru D, Ozçelik U, Kiper N, Aslan AT, Gözaçan A. Tracheomalacia and bronchomalacia in 34 children: clinical and radiologic profiles and associations with other diseases. Clin Pediatr (Phila). 2005;44(9):777-781. doi:10.1177/000992280504400905.

28. Farrell PM, White TB, Ren CL, et al. Diagnosis of cystic fibrosis: Consensus Guidelines from the Cystic Fibrosis Foundation. J Pediatr. 2017;181(suppl):S4-S15. doi:10.1016/j. jpeds.2016.09.064.

29. Cystic Fibrosis Foundation; Borowitz D, Robinson KA, Rosenfeld M, et al. Cystic Fibrosis Foundation evidence-based guidelines for management of infants with cystic fibrosis. J Pediatr. 2009;155(suppl):S73-S93. doi:10.1016/j.jpeds.2009.09.001.

30. Shapiro AJ, Davis SD, Polineni D, et al. Diagnosis of primary ciliary dyskinesia. An Official American Thoracic Society Clinical Practice Guideline. Am J Respir Crit Care Med. 2018;197(12):e24-e39. doi:10.1164/ rccm.201805-0819ST.

31. Shapiro AJ, Zariwala MA, Ferkol T, et al. Diagnosis, monitoring, and treatment of primary ciliary dyskinesia: PCD foundation consensus recommendations based on state of the art review. Pediatr Pulmonol. 2016;51(2):115-132. doi:10.1002/ppul.23304. 